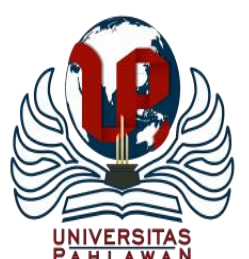

Jurnal Basicedu Volume 5 Nomor 1 Tahun 2021 Halaman 376-382

JURNAL BASICEDU

Research \& Learning in Elementary Education

https://jbasic.org/index.php/basicedu

\title{
Konsep dan Urgensi Penerapan School Well-Being pada Dunia Pendidikan
}

\author{
Aidia Rasyid \\ Universitas Islam Negeri Sultan Syarif Kasim Riau, Pekanbaru, Indonesia \\ Email : aidia.rasyid13@gmail.com
}

\begin{abstract}
Abstrak
Rendahnya pemahaman tentang konsep dan urgensi school well-being di sekolah menyebabkan berbagai penerapan kebijakan kurang memperhatikan kepada aspek well-being siswa. Padahal sekolah yang wellbeing merupakan konsep sekolah yang ideal diterapkan pada dunia pendidikan. Konsep school well-being terdiri dari empat dimensi yang bisa diterapkan yaitu having (kondisi sekolah), loving (hubungan sosial), being (pemenuhan diri) dan health (status kesehatan). Hasil studi literature ini adalah bahwa seluruh stake holder penting memperhatikan kondisi dari seluruh lingkungan fisik sekolah yang memberikan kebutuhan rasa aman dan nyaman bagi peserta didik dalam belajar. Kemudian hubungan sosial siswa yang dapat perhatian penuh seperti hubungan sosial sesama teman sebaya, dinamika kelompok, bullying atau perundungan yang terjadi di sekolah. Selanjutnya, hubungan sekolah dengan rumah, iklim sekolah mempunyai dampak pada well-being siswa. Pentingnya bagaimana sekolah menawarkan pendidikan untuk self actualization. Sekolah perlu mendukung program-progam yang berfokus untuk meningkatkan derajat kesehatan siswa, sehingga siswa dapat belajar dengan kondisi fisik dan jiwa yang sehat.
\end{abstract}

Kata Kunci: School well-being, having, loving, being, health

\begin{abstract}
The low understanding of the concept and urgency of school well-being in schools has resulted in various policy implementations less attention to the aspects of student well-being. Whereas a well-being school is an ideal school concept applied to the education. The concept of school well-being consists of four dimensions that can be applied, having (school conditions), loving (social relations), being (self-fulfillment) and health (health status). The results of this literature study are that all stakeholders are important to attention to the conditions of the entire physical school environment that provides the need for a sense of safe and comfort for students in learning. Then the students' social relationships that get full attention, such as peer social relationships, group dynamics, bullying that occurs at school. Furthermore, the relationship between school and home, school climate has an impact on students' well-being. The importance of how schools offer education for self actualization. Schools need to support programs that focus on improving the health status of students, so that students can learn with a physical health and mental health.
\end{abstract}

Keyword: School well-being, having, loving, being, health

Copyright (c) 2021 Aidia Rasyid

$\triangle$ Corresponding author

Address : Universitas Islam Negeri Sultan Syarif Kasim Riau

Email : aidia.rasyid13@gmail.com

ISSN 2580-3735 (Media Cetak)

DOI: https://doi.org/10.31004/basicedu.v5i1.705

ISSN 2580-1147 (Media Online) 


\section{PENDAHULUAN}

Sekolah ideal merupakan sekolah yang mampu mengaktualisasikan potensi siswa secara holistik sehingga membuat siswa-siswanya merasa sejahtera (well-being) karena kesejahteraan siswa (well-being) mempengaruhi hampir seluruh aspek bagi optimalisasi fungsi siswa di sekolah (Frost, 2010). Siswa merasa sejahtera ketika merasa aman, nyaman, bahagia dan sehat ketika di sekolah.

Konsep well-being didasarkan pada teori sosiologi tentang kesejahteraan (having, loving dan Being) dari Allard (Konu et al.2002). Kesejahteraan dan terkait konsep telah diukur menggunakan berbagai instrument yaitu indeks kepuasan hidup (Neugarten, 1961), kuesioner kesehatan umum (Goldberg, 1978), general wellbeing (Dupuy, 1984) dan Kebahagiaan Oxford (Argyle et al., 1987).

Konu \& Rimpela (2002) menjelaskan empat hal yang mempengaruhi SWB di sekolah yaitu kondsi lingkungan sekolah (fisik dan organisasi, layanan dan keamanan), relasi sosial (murid, guru, staf sekolah), pemenuhan diri (kesempatan belajar sesuai dengan kapabilitas, mendapatkan umpan balik, semangat), serta status kesehatan.

Konsep school well-being merupakan konsep yang aplikatif digunakan pada dunia pendidikan. Kempat dimensi School well-being belum dipahami oleh pengelola pendidikan dasar dan menengah secara holistic. Walaupun ini sudah dilaksanakan namun belum sistematis dan terencana dalam penerapan school well-being. Padahal school well-being di lingkungan sekolah memiliki peranan penting dalam keberhasilan belajar siswa.

Pemahaman tentang konsep school wellbeing sangat penting untuk mendorong berbagai tujuan pendidikan. Namun ada sebagian sekolah dalam penerapannya belum memahami konsep ini secara holostik dan sistematis. Oleh karena itu perlu kajian tentang "School-well Being Konsep dan Isu Penerapannya dalam dunia pendidikan".

\section{METODE}

Metode dalam penelitian ini adalah dengan metode studi literature, dimana peneliti mengumpulkan berbagai literature untuk mengkaji konsep dan urgensi school well-being bagi dunia pendidikan. Menurut Bungin (2006) studi literatur merupakan metode untuk mengumpulkan data historis pada penelitian sosial.

\section{HASIL DAN PEMBAHASAN}

School well-being merupakan sebuah konsep yang dikembangkan oleh Konu dan Rimpela berdasarkan teori well-being yang dikemukakan oleh Allardt. Allardt menjelaskan bahwa well-being merupakan suatu kondisi ketika kebutuhan-kebutuhan dasar dari seseorang dapat dipenuhi dengan baik, seperti kebutuhan berupa material dan non material (Hongwidjojo,et,al : 2018).

Menurut Diener 1984 (dalam Tian, 2008) menerangkan bahwa well-being adalah konstruk multidimensional yang berdampak pada sikap positif seperti emosi yang positif peserta didik. Kemudian jika Well-being negatif maka akan mempengaruhi emosi yang negative, misalnya kecemasan. Siswa yang memiliki Well-Being 
yang tinggi akan berpengaruh terhadap tingkat kepuasan hidup dan emosional positif.

$$
\text { Keyes dan Water-man (Bornstein, }
$$

Davidson, Keyes, \& Moore, 2003) menjelaskan bahwa school well-being merupakan hubungan sosial, teman dan waktu luang, volunteering, peran sosial, karakteristik kepribadian, kontrol diri dan sikap optimis, serta tujuan dan aspirasi. Hal ini didukung oleh penjelasan Pervin (Bornstein dkk, 2003) menyatakan bahwa individu yang memiliki rasa optimis mampu menyesuaikan diri dengan baik pada situasi tertentu seperti saat pergi ke sekolah. Konsep tersebut memiliki harapan bahwa kesejahteraan sekolah siswa sangat penting. Hal ini perlu diperhatikan seperti perasaan siswa dalam menilai kelayakan sekolah dalam proses belajar mengajar yang mampu memberikan dukungan, rasa aman, dan nyaman. Selain itu, keadaan rumah siswa dan lingkungan sekitar juga berpengaruh terhadap sekolah sehingga terbentuklah sebuah model school well-being.

Kebutuhan di sekolah meliputi empat dimensi yang dapat diperhatikan oleh seluruh stakeholder dalam mengambil kebijakan yaitu having,loving being dan health.Berikut digambarkan dalam bagan dibawah ini :

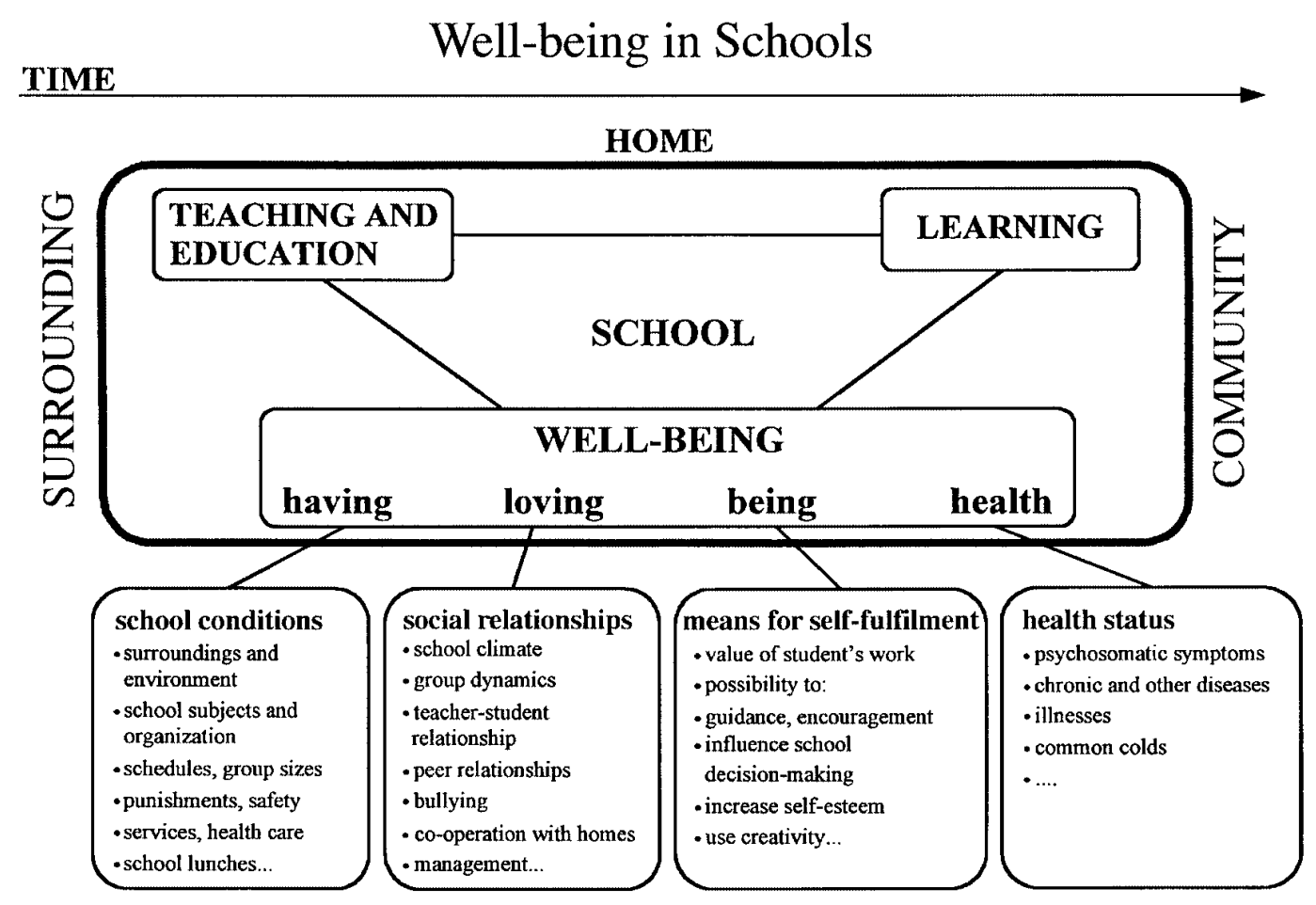

Gambar 1 : Bagan Model School Well being ( Konu \& Rimpela : 2002)

Model School Well-Being (Gambar 1) merupakan konsep kesejahteraan dalam sekolah sebagai fenomena empat dimensi. Kesejahteraan dikaitkan dengan pengajaran dan pendidikan di satu sisi, dan dengan pembelajaran dan pencapaian, di sisi lain. Kesejahteraan dibagi menjadi kondisi sekolah dikembangkan setelah tinjauan sosiologis yang sesuai, promosi pendidikan, psikologis dan literature kesehatan.

Program school well-being sangat penting diterapkan karena siswa akan bahagia dan sejahtera saat mengikuti pembelajaran, selain itu 
siswa dapat berkontribusi aktif di sekolah. Berikut dijelaskan keempat dimensi dari school well-being

\section{Having}

Dimensi pertama yaitu kondisi dari seluruh lingkungan fisik sekolah yang memberikan kebutuhan rasa aman dan nyaman bagi peserta didik dalam belajar. Kemudian lingkungan belajar yang terdiri dari kurikulum sekolah, jadwal pelajaran dan hukuman. Pelayanan sekolah seperti pelayanan guru bimbingan konseling dan wali kelas. Pelayanan kesehatan dan pelayanan untuk kebutuhan dasar siswa sperti makan siang (Konu Rimpela : 2002). Kondisi sekolah ini yang perlu menjadi perhatian stake holder terdiri dari
a. Lingkungan dan Sekitarnya surrounding and environment)
b. School Subject and Organization
c. Jadwal dan Ukuran kelompok
d. Hukuman and Keamanan
e. Layanan dan peduli kesehatan
f. Makan Siang Sekolah

2. Loving

Dimensi kedua dari SWB adalah loving (hubungan sosial). Hubungan sosial siswa dalam dapat diperhatikan oleh tenaga pendidik dan kependidikan, hubungan sosial sesama teman sebaya, dinamika kelompok, bullying atau perundungan yang terjadi di sekolah. Hubungan sekolah dengan rumah, iklim belajar siswa. Iklim sekolah mempunyai dampak pada kesejahteraan dan kepuasan siswa di sekolah. Terciptanya hubungan yang baik akan berdampak pada prestasi siswa di sekolah. Ada beberpa aspek dari hubungan
Hubungan sosial yang dapat diperhatikan oleh stakeholder yaitu :
a. Iklim sekolah
b. Dinamika Kelompok
c. Hubungan Guru dengan Murid
d. Hubungan dengan teman sebaya
e. Bullying
f. Kooperatif dengan rumah
g. Managemen

Kondisi lingkungan sosial seperti hubungan siswa dengan teman sekelas, hubungan pendidik dan siswa, dinamika kelompok serta membangun kerjasama seluruh civitas sekolah merupakan hal yang perlu diperhatikan. Perilaku bullying Menurut Putri et al dlama (Anggreni, 2019) interaksi antara teman sebaya dapat mendidik anak untuk mampu bersosisialisai dan menekan agresi.

Hasil penelitian Usman dalam (Anggreni, 2019) menunjukkan bahwa iklim sekolah yang baik akan mengurangi perilaku bullying siswa. Iklim tercipta jika komunikasi yang efektif antara siswa guru dan staff. Selanjutnya Sekolah seharusnya menerapkan lingkungan yang aman, nyaman, memperhatikan kebisingan, ventilasi, suhu udara, dapat dilakukan dengan mendekorasi ruangan kelas yang terlihat ceria, berbagai hasan dinding.

Selanjutnya yang perlu diperhatikan yaitu aspek kurikulum, seperti kegitan belajar mengajar tugas yang flexibe akan membentuk school-well being siswa disekolah.

\section{Being}


Dimensi ketiga adalah being dengan arti Pemenuhan diri. Dalam konteks ini sekolah, yang being dapat dilihat dengan bagaimana sekolah menawarkan pendidikan untuk self actualization. Setiap siswa menjadi aspek penting dalam komunitas sekolah. Setiap kebijakan sekolah memungkinkan setiap siswa untuk berpartisipasi dalam pengambilan keputusan dari sekolahnya.

Peluang siswa untuk memperbearui skill dan pengetahua siswa perlu diperhatikan oleh sekolah (Konu \& Rimpela, 2002). Berikut beberapa poin yang perlu diperhatikan tenatang pemenuhan diri :

a. Penilaian dari pekerjaan siswa

b. Bimbingan Konseling dan pemberian semangat

c. Pengaruh sekolah dalam pembuatan keputusan

d. Penigkatan harga diri

e. Menggunakan kreatifitas

Siswa dapat berpartisipasi dalam pengambilan keputusan di sekolahnya. Kesempatan dalam pengambilan keputusan penting untuk meningkatkan pengetahuan dan keterampilan bagi siswa dan sekolah mendukung siswa setiap proses pembelajaran.

4. Health

Aspek keempat adalah Health (status kesehatan) meliputi aspek fisik dan mental berupa symtomps psikosomatis, penyakit kronis, penyakit ringan (seperti flu), dan penghayatan akan keadaan diri (Konu \& Rimpela, 2002). Well-being dapat dilihat dari dua indikator, yakni indikator objektif dan indikator subjektif. Indikator objektif didasarkan pada observasi eksternal dan indikator subjektif didasarkan pada ekspresi orang terhadap sikap mereka dan persepsi mereka terhadap kondisi lingkungannya (Konu \& Rimpela, 2002). Status kesehatan

a. Simptoms

b. Symptomps Psikosomatis

c. Wabah dan lainnya

d. Penyakit

e. Flu biasa

Siswa semestinya mendapatkan perhatian terkait dengan isu-isu kesehatan di sekolah. Sekolah perlu mengefektifkan dan mendukung program-progam UKS yang berfokus untuk meningkatkan drajat kesehatan siswa, sehingga siswa dapat belajar dengan kondisi fisik dan jiwa yang sehat. Menurut Chistner \& Mennuti dalam (Anggreni, 2019) hal yang tidak kalah penting yaitu tersedia layanan bimbingan konseling untuk memperhatikan berbagai aspek kesehatan mental siswa. Hal tersebut perlu kolaborasi antara seluruh civitas academika sehingga tercipta perkembangan peserta didik yang optimal.

Berbagai penelitian tentang school wellbeing menunjukan pentingnya diaplikasikan school well-being pada dunia pendidikan. Diantaranya penelitian Irene tentang gambaran school well-being pada peserta didik program kelas akselerasi SMA Negeri 8 Yogyakarta, menemukan bahwa siswa tidak merasa nyaman ketika berada di sekolah disebabkan manajemen pembelajaran sekolah seperti buku ajar yang kurang, koneksi internet yang masih sukar untuk dijangkau, waktu belajar yang sangat padat serta 
waktu istirahat yang dirasakan tidak cukup. Kemudian faktor-faktor yang berkontribusi terhadap school well-being pada siswa akselerasi yaitu faktor eksternal yang meliputi infrastruktur yang baik, managemen sekolah, interaksi dengan guru maupun teman sekolah baik dan dukungan orangtua. Sedangkan faktor internal adalah modal dasar personal siswa yang sudah dimiliki seperti motivasi yang tinggi, disiplin yang tinggi, kerjasama yang baik, memiliki inisiatif belajar yang tinggi serta mampu menciptakan strategi belajar yang baik.

Selanjutnya penelitian Opdenakker \&Damme (2000) menemukan ada pengaruh staff pengajar, dan kelas terhadap preastasi dan wellbeing dari sekolah menengah. Studi tersebut menegaskan bahwa pengaruh sekolah, staff dan kelas pada prestasi lebih tinggi daripada wellbeing. Riset Faizah et.al (2020) menunjukkan terdapat perbedaan school well-being pada siswa SD dan SMP sistem full day. Siswa SD memiliki school well-being yang lebih tinggi dibandingkan siswa SMP. Temuan penelitian ini adalah bahwa school well-being siswa SD lebih tinggi dari SMP yang melaksanakan fullday.

Selanjutnya Direktur P3GTK (2020) menjelaskan bahwa school well being dilaksanakan di sekolah dengan cara menggerakkan semua jaringan dengan saling bersinergi, monitoring, supervisi, dan pelatihan atau edukasi bagi pendidik dan peserta didik . School wellbeing juga mendorong tumbuh kembang siswa secara holistik dengan enam profil pelajar pancasila sebagai indikator capaiannya, menjadi teladan dan agen perubahan serta menjadi pelatih bagi guru lain. Kebijakan tersebut didukung oleh penelitian Lohre dalam Ratna (2016) bahwa kesejahteraan siswa di sekolah menjadi lebih baik jika ada dukungan dari pihak eksternal seperti kondisi sekolah, hubungan sosial dengan seluruh warga sekolah, serta siswa mampu megaktualisasikan diri di sekolah serta sekolah yang memperhatikan layanan kesehatan.

\section{SIMPULAN}

Penerapan school well- being yang memperhatikan empat dimensi seperti having, loving, being dan health merupakan konsep sekolah yang ideal yang dapat diterapkan pada dunia pendidikan. Oleh karena itu dengan memahami konsep school well being dapat mendorong sekolah untuk membuat programprogram dan kebijakan yang meperhatikan empat dimensi dari school well-being.

\section{DAFTAR PUSTAKA}

Anggreni N M, Immanuel A.S. (2019). School Well Being adalah Sekolah Impianku. Buletin KPIN, Vol.5 No. 12.

Bungin B. (2006). Metodelogi Penelitian Kualitatif; Aktualisasi Metodologis ke Arah Ragam Varian Kontemporer. Jakarta: Raja Grafindo

Faizah, et al. (2020). School Well-Being Siswa Sekolah Dasar dan Siswa Sekolah Menengah Pertama Pengguna Sistem Full-Day School di Indonesia, Jurnal Kajian Bimbingan dan Konseling, Vol 5 (1), hlm. 34-41

Frost. 2010. The Effectiveness of Student Wellbeing Program and Service. Melbourne: Victorian Auditor-General's Report.

Khatimah H. 2015. Gambaran School Well-Being pada Peserta Didik Program Kelas Akselerasi di SMA Negeri 8 Yogyakarta, 
382 Konsep dan Urgensi Penerapan School Well-Being pada Dunia Pendidikan - Aidia Rasyid DOI: https://doi.org/10.31004/basicedu.v5i1.705

Psikopedagogia. Vol. 4, No.1, hlm. 2030.

Hongwidjojo M.P.M, \& Monika,Wijaya E. 2018. Relation of Student-Teacher Trust with School Well-Being to High School Students, Journal Psikodimensia, Vol. 17, No. 2, hlm.162-167

Gilmore, Soutter,K.A., \& O'Steen,B. (2012). Students' and teachers' perspectives on wellbeing in a senior secondary environment. Journal of Student Wellbeing , 13 Vol. 5 (2), 34-67.

Konu, A.,Lintonen, T \& Rimpela,M, 2002. Factor structure of the School Well-being Model. Health Education Research .Vol.17. No.6 HLM. 732-742

Konu, A., \& Rimpela, M. (2002). Well-being in school: A Conceptual Model. Health Promotion International, Vol. 17 (1). Hlm. 79 - 89.

Opdenakker M.C. Damme JV. 2000. Effects of Schools, Teaching Staff and Classes on Achievement and Well-Being in Secondary Education: Similarities and Differences Between School Outcomes, School Effectiveness and School Improvement. Vol. 11. No. 2. Hlm. 165196

Ratna C.T, 2016. Strategi School Well-Being di Sekolah Menengah Atas (SMA) sebagai Alat Evaluasi Sekolah. Seminar ASEAN $2^{\text {nd }}$ Psychology \& Humanity (CPsychology Forum UMM, $19-20$ Februari 2016. Hlm76-79.

https://p3gtk.kemdikbud.go.id/konten/mewujudkan -school-well-being-dalam-sekolah-kita86qzocw8, diakses 25 November 2020 